\title{
Low RF Complexity Photonically Enabled Indoor and Building-to-Building W-Band Wireless Link
}

Rommel, Simon; Cavalcante, Lucas Costa Pereira; Vegas Olmos, Juan José; Tafur Monroy, Idelfonso

Published in:

Proceedings of Asia Communications and Photonics Conference 2015

Publication date:

2015

Document Version

Publisher's PDF, also known as Version of record

Link back to DTU Orbit

Citation (APA):

Rommel, S., Cavalcante, L. C. P., Vegas Olmos, J. J., \& Tafur Monroy, I. (2015). Low RF Complexity

Photonically Enabled Indoor and Building-to-Building W-Band Wireless Link. In Proceedings of Asia Communications and Photonics Conference 2015

\section{General rights}

Copyright and moral rights for the publications made accessible in the public portal are retained by the authors and/or other copyright owners and it is a condition of accessing publications that users recognise and abide by the legal requirements associated with these rights.

- Users may download and print one copy of any publication from the public portal for the purpose of private study or research.

- You may not further distribute the material or use it for any profit-making activity or commercial gain

- You may freely distribute the URL identifying the publication in the public portal 


\title{
Low RF Complexity Photonically Enabled Indoor and Building-to-Building W-Band Wireless Link
}

\author{
Simon Rommel, Lucas C. P. Cavalcante, J. J. Vegas Olmos, Idelfonso Tafur Monroy \\ Department of Photonics Engineering, Technical University of Denmark, 2800 Kgs. Lyngby, Denmark \\ sirem@fotonik.dtu.dk
}

\begin{abstract}
We demonstrate W-band wireless transmission over distances covering both indoor and building-to-building scenarios with a setup of reduced complexity in the RF domain, employing a passive wireless transmitter and envelope detection at the receiver.
\end{abstract}

OCIS codes: (060.5625) Radio frequency photonics; (060.4510) Optical communications.

\section{Introduction}

The introduction and increasing use of a variety of bandwidth intensive services and applications-including e-health monitoring, distance learning, high resolution video streaming and holographic video conferencing — on portable consumer devices has lead to an increased demand for high-speed wireless connections. The high bandwidth requirements of such applications are beyond the capacity of the already congested conventional wireless bands and a migration to higher frequency bands supporting greater transmission bandwidths—-such as the millimeter-wave ( $\mathrm{mmW})$ region-is necessary [1-4].

While currently the V-band and especially carriers at $60 \mathrm{GHz}$ are the dominant focus for Gbit/s indoor wireless [3] this region is affected by a large peak in atmospheric absorption [1], severely limiting it to short-range transmissions. The W-band $(75 \mathrm{GHz}$ to $110 \mathrm{GHz}$ ) however does not share this limitation and may thus be a candidate for both indoor and building-to-building transmission scenarios [3,5] as shown in Fig. 1.

Long distance Gbit/s class W-band wireless transmission has been demonstrated with high complexity in both the optical and radio frequency (RF) parts of the system, while on the contrary recent demonstrations with reduced complexity and employing envelope detection have not reached beyond $10 \mathrm{~m}$ wireless transmission $[6,7]$.

In this paper we demonstrate $\mathrm{W}$-band wireless transmission with a reduced-complexity setup employing a passive wireless transmitter and a Schottky diode based envelope detection receiver. We analyze system performance and requirements for error free transmission and their dependency on both wireless distance and RF carrier frequency. By investigating RF carriers between $75 \mathrm{GHz}$ and $87 \mathrm{GHz}$ and wireless distances of $20 \mathrm{~m}$ to $70 \mathrm{~m}$ we cover the lower half of the W-band for both indoor and building-to-building scenarios as shown in Fig. 1.

\section{Experimental Setup}

The W-band transmission setup with low complexity in the radio-frequency (RF) domain is depicted in Fig. 3 while Fig. 2 shows the corresponding laboratory setup. Photonic up-conversion is employed at the transmitter, consisting of an external cavity laser (ECL) at $\lambda=1550 \mathrm{~nm}$ for signal generation, followed by a Mach-Zehnder modulator (MZM) driven with a sinusoidal at $f_{R F} / 2$ to generate two spectral lines spaced at $f_{R F}$. While the wavelength of the ECL is constant, the driving frequency for the MZM is varied in order to generate line spacings between $75 \mathrm{GHz}$ and $87 \mathrm{GHz}$.

The signal is amplified and an arrayed waveguide grating (AWG) separates the two lines while suppressing the original signal, allowing one line to be modulated in a second MZM. The latter is driven at data rates of $2 \mathrm{Gbit} / \mathrm{s}$ and $2.5 \mathrm{Gbit} / \mathrm{s}$ by a $2^{15}-1$ bit long pseudo-random bit sequence (PRBS15) non-return-to-zero (NRZ) signal from a pulse pattern generator (PPG). The lines are recombined, amplified and transmitted through $10 \mathrm{~km}$ of ITU-T G.652 standard single-mode fiber (SMF).

At the transmit antenna a variable optical attenuator (VOA) allows variation of the power incident on the photodiode (PD) between $0 \mathrm{dBm}$ and $8 \mathrm{dBm}$, thus giving control over the power of the output RF signal at $f_{R F}$ resulting from the beating of the two signal lines on the PD. A pair of parabolic antennas-with a gain of $48 \mathrm{dBi}$ each—allows wireless transmission of the RF signal over distances between $20 \mathrm{~m}$ and $70 \mathrm{~m}$.

The received W-band signal is amplified with the help of a low noise amplifier (LNA) providing $40 \mathrm{~dB}$ gain before down-conversion takes place in a Schottky diode based envelope detector (ED) with a $3 \mathrm{~dB}$ bandwidth of $3 \mathrm{GHz}$. 


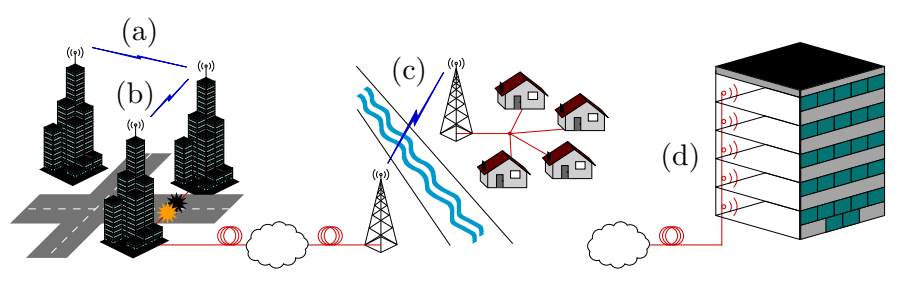

Fig. 1. Network scenarios for the hybrid fiber-wireless link. (a)-(c) outdoor medium distance links: (a) building-to-building communication, (b) recovery and protection of fiber links, (c) spanning obstacles and providing broadband access to rural ares; (d) short-range indoor wireless distribution

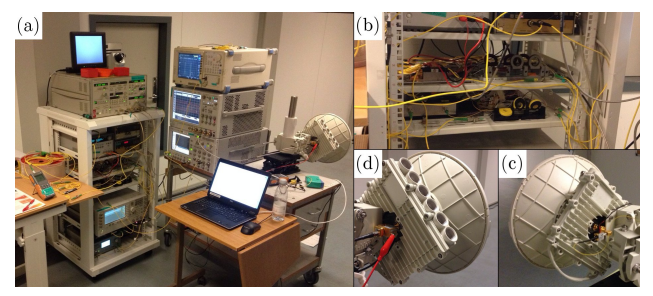

Fig. 2. (a) Portable laboratory setup with photonic upconversion, (b) Rack-mounted optical setup, (c) Transmit antenna with PD, (d) Receive antenna with LNA and ED

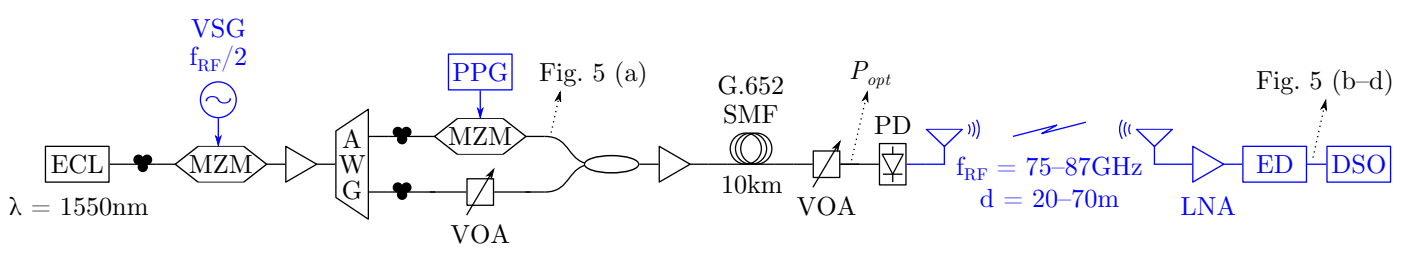

Fig. 3. Experimental setup for radio-over-fiber transmission. ECL: external cavity laser, VSG: vector signal generator, MZM: Mach-Zehnder modulator, AWG: arrayed waveguide grating, PPG: pulse pattern generator, VOA: variable optical attenuator, SMF: single-mode fiber, PD: photodiode, LNA: low noise amplifier, ED: envelope detector, DSO: digital storage oscilloscope

Employing envelope detection rather than down-conversion with an electrical mixer alleviates the need for a local oscillator at the receiver and thus - together with employing a passive wireless transmitter and only a single LNA at the receiver-minimizes complexity of the RF chain at both ends. Finally the received baseband signal is recorded using a digital storage oscilloscope (DSO) and bit-error rate (BER) values are determined through offline processing, consisting of simple thresholding and error counting over four recorded sequences with a combined length $>10 \mathrm{Mbit}$.

With both RF carrier frequency and optical power incident on the photodiode tunable, this setup allows analysis of transmission performance over a parameter space spanning the lower half of the W-band and for transmission distances covering typical indoor environments as well as a number of building-to-building scenarios as shown in Fig. 1.

\section{Experimental Results}

In this work we analyze the transmission performance of a W-band hybrid photonic-wireless link transmitting over $10 \mathrm{~km}$ SMF and wireless distances between $20 \mathrm{~m}$ and $70 \mathrm{~m}$, employing RF carrier frequencies between $75 \mathrm{GHz}$ and $87 \mathrm{GHz}$. Fig. 4 (a) shows BER as a function of power on the PD and its dependency on wireless carrier frequency. While the general trend confirms the prediction of the Friis free-space loss model that required transmit power increases with carrier frequency due to increased path loss, it is clear that performance across the regarded frequency band is dominated by the variation of the involved RF equipment, rather than the frequency dependent loss which amounts to only $1.3 \mathrm{~dB}$ extra loss when comparing RF carriers at $75 \mathrm{GHz}$ and $87 \mathrm{GHz}$.

Fig. 4 (b) shows BER as a function of both power on the PD and distance (the displayed BER of $10^{-7}$ at the high powers indicates successful and error free transmission for the analyzed sequences with a combined length $>10 \mathrm{Mbit}$ ), while Fig. 5 gives a comparison of transmitter and receiver eye diagrams and shows the evolution of the latter with wireless distance at a fixed optical power of $5 \mathrm{dBm}$. The correlation between transmission distance and required optical power is immediately visible and at a BER of $10^{-6}$ minimum optical powers of $0.7 \mathrm{dBm}$ and $4.4 \mathrm{dBm}$ are found for distances of $40 \mathrm{~m}$ and $70 \mathrm{~m}$ respectively. The translation of this increase in optical power to resulting transmitted $\mathrm{RF}$ power compares well with the increase necessary to overcome the additional loss of $4.9 \mathrm{~dB}$ resulting from the increased transmission distance. With as much as $3 \mathrm{~dB}$ in additional optical power available at the $\mathrm{PD}$, an increase in wireless distance well beyond the mark of $100 \mathrm{~m}$ is expected to be within the power budget of the presented system. 

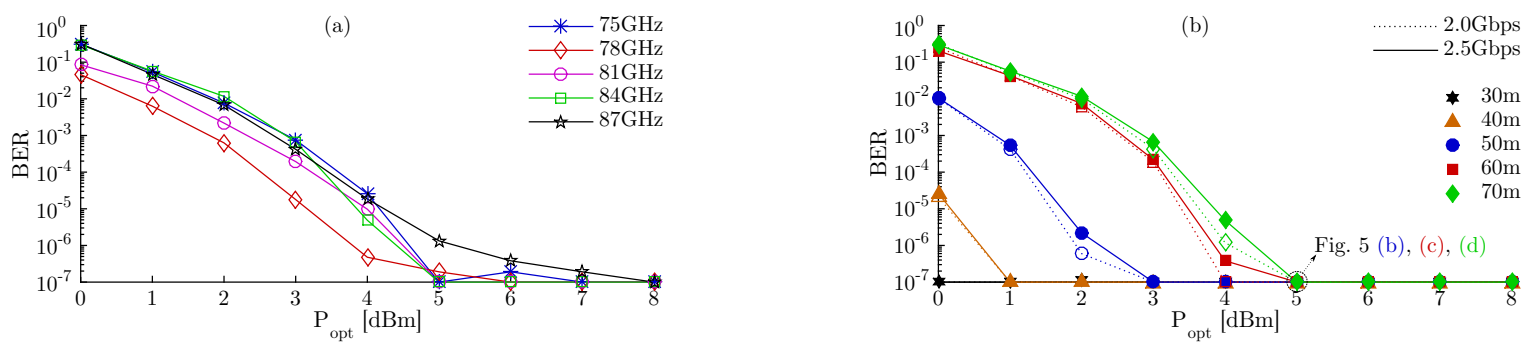

Fig. 4. Evolution of BER vs $P_{\text {opt }}$ : (a) for different RF carrier frequencies at $2.5 \mathrm{Gbit} / \mathrm{s}$ and after $70 \mathrm{~m}$ wireless transmission, (b) for wireless transmission distances between $30 \mathrm{~m}$ and $70 \mathrm{~m}$ at data rates of $2 \mathrm{Gbit} / \mathrm{s}$ and $2.5 \mathrm{Gbit} / \mathrm{s}$ and with an RF carrier frequency of $84 \mathrm{GHz}$
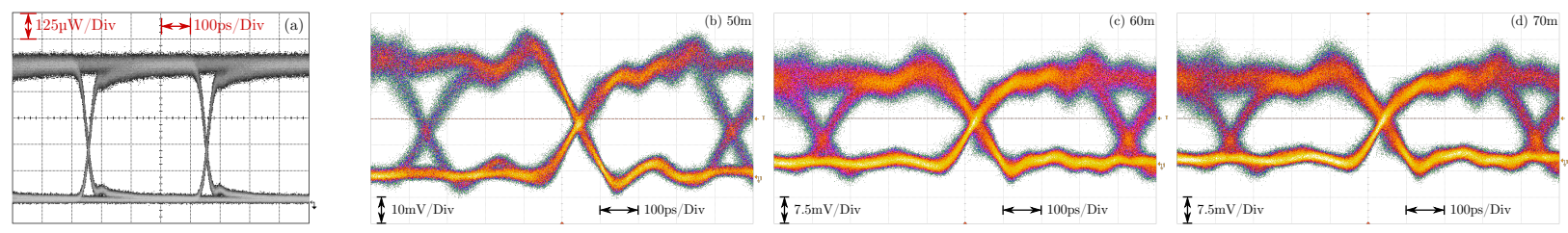

Fig. 5. Eye diagrams: (a) transmitter $2.5 \mathrm{Gbit} / \mathrm{s}$ NRZ signal, (b) receiver after envelope detection of the $2.5 \mathrm{Gbit} / \mathrm{s}$ NRZ signal on an $84 \mathrm{GHz} \mathrm{RF}$ carrier and $10 \mathrm{~km} \mathrm{SMF}$ and $50 \mathrm{~m}$ to $70 \mathrm{~m}$ wireless transmission for $P_{o p t}=5 \mathrm{dBm}$

\section{Conclusions}

We have demonstrated W-band wireless transmission with a setup of reduced complexity in the RF domain, avoiding down-mixing by employing envelope detection at the receiver and minimizing the number of RF amplifiers through the use of a passive wireless transmitter. Transmission with a BER $<10^{-6}$ was achieved over distances between $20 \mathrm{~m}$ and $70 \mathrm{~m}$ and with RF carriers between $75 \mathrm{GHz}$ and $87 \mathrm{GHz}$, giving a good indication of the performance achievable in the W-band even with reduced complexity setups and covering typical indoor and building-to-building scenarios.

\section{Acknowledgments}

The authors thank Siklu Communication Ltd. for providing the antennas. This work was partly funded by the DFF FTP mmW-SPRAWL and EC IPHOBAC-NG projects. L. Cavalcante thanks the Science without Borders program.

\section{References}

[1] J. Wells, "Faster than fiber: The future of multi-G/s wireless," IEEE Microw. Mag. 10, pp. 104-112 (2009).

[2] K.-i. Kitayama, T. Kuri, J. J. Vegas Olmos, and H. Toda, "Fiber-Wireless Networks and Radio-over-Fibre Technique," in Proc. CLEO 2008 (OSA, San Jose, 2008), paper CThR4.

[3] H. Yang, A. Ng'oma, B. Shih, A. Gowda, and L. Kazovsky, "Fiber-based Solutions for In-door Multi-Gbit/s Wireless Access," in Proc. OFC 2015 (OSA, Los Angeles, 2015), paper W3F.1.

[4] S. Rommel, A. Galvis Quintero, L. C. P. Cavalcante, J. J. Vegas Olmos, and I. Tafur Monroy, "Channel Characterization for High-Speed W-Band Wireless Communication Links," in Proc. OECC 2015 (Shanghai, 2015).

[5] X. Pang, A. Lebedev, J. J. Vegas Olmos, and I. Tafur Monroy, "Multigigabit W-Band (75-110 GHz) Bidirectional Hybrid Fiber-Wireless Systems in Access Networks," J. Lightw. Technol. 32, pp. 3983-3990 (2014).

[6] A. Stöhr et al., "Robust 71-76GHz Radio-over-Fiber Wireless Link with High-Dynamic Range Photonic Assisted Transmitter and Laser Phase-Noise Insensitive SBD Receiver," in Proc. OFC 2014 (OSA, San Francisco, 2014), paper M2D.4.

[7] C.-H. Li, M.-F. Wu, C.-H. Lin, and C.-T. Lin, "W-band OFDM RoF System with Simple Envelope Detector Down-Conversion,” in Proc. OFC 2015 (OSA, Los Angeles, 2015), paper W4G.6. 